\title{
Reducing computing time of energy system models by a myopic approach
}

\author{
A case study based on the PERSEUS-NET model
}

\author{
Sonja Babrowski - Tobias Heffels • \\ Patrick Jochem • Wolf Fichtner
}

\begin{abstract}
In this paper, the performance of the existing energy system model PERSEUS-NET is improved in terms of computing time. Therefore, the possibility of switching from a perfect foresight to a myopic approach has been implemented. PERSEUS-NET is a linear optimization model generating scenarios of the future German electricity generation system until 2030, whilst considering exogenous regional characteristics such as electricity demand and existing power plants as well as electricity transmission network restrictions. Up to now, the model has been based on a perfect foresight approach, optimizing all variables over the whole time frame in a single run, thus determining the global optimum. However, this approach results in long computing times due to the high complexity of the problem. The new myopic approach splits the optimization into multiple, individually smaller, optimization problems each representing a 5 year period. The change within the generation system in each period is determined by optimizing the subproblem, whilst taking into account only the restrictions of that particular period. It was found that the optimization over the whole time frame with the myopic approach takes less than one tenth of the computing time of the perfect foresight approach. Therefore, we analyse in this paper the advantages and draw-backs of a change in the foresight as a way of reducing the complexity of energy system models. For PERSEUS-NET it is found that the myopic approach with stable input parameters is as suitable as the perfect foresight approach to generate consistent scenarios, with the advantage of significantly less computing time.
\end{abstract}

Keywords Myopic $\cdot$ Perfect foresight · Energy system modelling · PERSEUS

S. Babrowski $(\varangle) \cdot$ T. Heffels $\cdot$ P. Jochem $\cdot$ W. Fichtner

Chair of Energy Economics, Institute for Industrial Production (IIP),

Karlsruhe Institute of Technology (KIT), Hertzstraße 16, 76187 Karlsruhe, Germany

e-mail: Sonja.Babrowski@kit.edu 


\section{List of symbols}

\section{Indices}

DEMPROC

ec

$\mathrm{EC}_{\text {seas }}, \mathrm{EC}_{\text {non-seas }}$

elec

exp

\section{GENPROC}

Imp

kyo

proc

prod

seas

$\mathrm{t}$

unit

\section{Parameters}

Avai $_{\text {unit,t }}$

$\alpha_{\mathrm{t}}$

$\lambda_{\text {proc,ec }}$

$\eta_{\text {prod,prod }}{ }^{\prime}, \mathrm{ec}, \mathrm{t}$

$\eta_{\text {proc }, \mathrm{t}}$

CapRes $_{\text {unit,t }}$

Cfix unit,t

Cfuel $_{\text {imp,prod }}{ }^{\prime}, \mathrm{ec}$

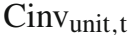

$\mathrm{CkyO}_{\mathrm{kyo}, \mathrm{t}}$

Cload $_{\text {unit,t }}$

Cvar $_{\text {proc, } t}$

$\mathrm{D}_{\mathrm{t} \text {, seas }}$

$\mathrm{h}_{\text {seas }}$

\section{Variables}

Capunit,t

$\mathrm{Fl}_{\text {imp,prod }}$,ec,t

$\mathrm{Fl}_{\text {prod,prod }}, \mathrm{ec}, \mathrm{t}$
Demand processes

Energy carriers and materials ( $e c \in E C$ )

Seasonal and non-seasonal energy carriers

Electricity as energy carrier

Sinks of the graph structure $(\exp \in E X P)$

Generation processes

Sources of the graph structure (imp $\in I M P$ )

$\mathrm{CO}_{2}$ emission allowances $(k y p \in K Y O)$

Processes (proc $\in P R O C$ )

Producers $($ prod $\in P R O D)$

Time slots (seas $\in$ SEAS)

Year, period $(t \in T)$

Units (unit $\in U N I T$ )

Availability factor for the generation unit unit in period $t$

Discount factor

Share of energy carrier ec related to total input/output of the process proc

Flow efficiency of energy carrier $e c$ between producers prod and prod'

Efficiency of process proc in period $t$

Installed capacity of unit unit at the beginning of period $t$

Fixed annual operation costs of the generation unit unit in period

Fuel costs for the delivery of the energy carrier ec to producer prod' in period $t$

Specific investment for commissioning the generation unit unit in period $t$

Costs for the acquisition of $\mathrm{CO}_{2}$ allowances from the contingent kyo in period $t$

Load change costs for the generation unit unit in period $t$

Variable operating costs of the process proc in period $t$

Demand for electricity in time slice seas in period $t$

Number of hours in season seas

Installed capacity of the generation unit unit in period $t$

Level of $e c$-flow from the source of the graph structure imp to producer prod' per year

Level of $e c$-flow from producer prod' to producer prod per year 


$\mathrm{Fl}_{\text {prod,exp,ec,t }}$
$\mathrm{FS}_{\text {prod,prod',ec,t,seas }}$
$\mathrm{FS}_{\text {prod,exp,ec,t, seas }}$
KyoCert $_{\text {kyo,t }}$
LVchange $_{\text {unit, seas }-1, \text { seas,t }}$
NewCapunit, $\mathrm{t}$
$\mathrm{PL}_{\text {proc,t }}$
$\mathrm{PS}_{\text {proc,t, seas }}$

Level of ec-flow from producer prod to the sink of the graph structure exp per year

Level of ec-flow from producer prod' to producer prod per time slot

Level of $e c$-flow from producer prod to the sink of the graph structure $\exp$ per year

Procurement of $\mathrm{CO}_{2}$ allowances kyo in period $t$

Load change of generation unit unit between time slices seas- 1 and seas in $t$

Newly installed capacity of generation unit unit in a period $t$

Activity level of process proc per year in period $t$

Activity level of process proc in time slot seas in period $t$

\section{Introduction}

Energy system modelling is a common approach for analysing the potential development of the generation system as a reaction to given circumstances, such as different policies and changes in primary resource prices. The short-sightedness of policy makers and the volatility of fuel prices make long-term forecasts increasingly difficult. Nevertheless, in the energy sector with capital-intensive investments and long-lasting assets, the success of investments depends strongly on the underlying scenarios of the considered time horizon. Therefore, energy system models are essential to generate a basis for decisions. Their results should be, however, understood not as forecasts but as what-if analyses, quantifying the effects of the corresponding assumptions like policy measures.

One means of performing such what-if analyses are optimizing bottom-up energy system models. In such models the energy demand, for example for fuel, electricity and/or heat has to be satisfied by a given market and/or given technology options, while for instance the costs to do so are minimized. Because of the high complexity of the energy system the corresponding models are extensive and include a large number of variables, parameters, restrictions and assumptions. The more precise the mapping of the reality is represented, the more complex the underlying equations are composed and the more data is to be processed and the higher the resulting computing time becomes. In order to have a feasible computing time, detailed optimizing energy system models tend to be modelled as linear problems, avoiding mixed integer or nonlinear problems that have a comparably higher computing time. Thus restrictions are linearized and as models reach a certain size the time resolution has to be decreased. This enables the user to achieve reliable results on common computers in reasonable computing times and to avoid high performance computer access. In short, a trade-off between exactness and computing time has to be made.

Energy system models are broadly applied in energy economics to assist in making investment decisions and/or the dispatching of power plants based on assumptions of the future energy system [1-4]. In the years to come, the complexity of the energy 
system will increase due to a raising share of renewable resources and the decentralisation of the electricity provision [5]. A growing importance of renewable feed-in leads to the need for a high time resolution in energy system models as the feed-in can change quickly, challenging the energy system to a quick and sometimes short-term reaction. At the same time, the growing decentralisation requires a high regional resolution to depict energy flows correctly. This is especially true for the German electricity system, which is expected to have more than $80 \%$ electricity by renewable resources by 2050 [6]. Hence, the electricity generation is less controllable and imposing the pressure on the underlying grid and electricity demand. Therefore, energy system models should consider regional effects (i.e. the grids) and improve the temporal resolution in order to recognize the fluctuating wind supply. This fosters the complexity of these models significantly.

In order to cope with the complexity of modern energy system models and meet the challenges in terms of keeping the computing time feasible we could either use high performance computers or optimise other model specific characteristics (e.g. algorithms, solvers). As there have recently already been several versions of international known energy system models that changed the considered time-horizon from perfect foresight to a myopic sight [7-9] we concentrate in this paper on analysing the advantages and draw-backs of this change as a way of reducing the complexity of energy system models. We enhance the performance of the energy system model PERSEUSNET through replacing the usually applied perfect foresight approach by a myopic (or time step) approach. While the perfect foresight approach finds the intertemporal optimum over the whole time frame, the myopic approach returns the optimum for each of the considered periods without setting them in the context with the other periods. Future developments are neglected. This could lead-as in the case of PERSEUSNET - to a resulting time saving of several hours or days and, hence, keep the model development more flexible.

In order to analyse the advantages and drawbacks of optimizing energy system models using myopic approaches instead of perfect foresight approaches, the paper is structured as follows. In the next section the theoretical background and a short review of other energy system models with a myopic approach is given before in Sect. 3 the energy system model PERSEUS-NET is introduced which serves as the reference model for the following analysis. At first the features of PERSEUS-NET are explained before in Sect. 3.2 the computational realization of the implementation of the new approach is illustrated. Section 4 introduces two exemplary scenarios, which are used to determine the differences in the results and computing time of the myopic and the perfect foresight approach. In Sect. 5 the assets and drawbacks of the two approaches are discussed before in Sect. 6 the outcomes of this study are summarized and an outlook on future fields of research is given.

\section{Scientific context}

The terms myopic and perfect foresight refer to the way in which expectations of economic actors are represented in the model. In a perfect foresight model, the economic actors know exactly how energy demand and energy carrier prices will develop 
into the future. Thus the solution represents an optimal allocation of resource usage over the whole timeframe, i.e. the global optimum. In contrast, in the myopic model, the economic actors base their decisions only on the given price and demand scenarios in the period of the decision. Thus decisions are made as if energy carrier prices and electricity demand would remain unchanged after the current period. The consequence is, firstly, that the model's solution based on perfect foresight will have lower total costs, as it can anticipate energy carrier price developments, for example, and make investments in new generation capacity accordingly. Another consequence of the approach is that the optimization problem of the perfect foresight approach is split into several, individually smaller optimization problems: one for each calculated period. These sub-problems can be solved in fractions of the time it takes to solve the original problem. Especially during the calibration or expansion of a model this facilitates the work for the model developer, since in this case many dozen model runs have to be executed. In the myopic model often only one period has to be calculated in order to verify a new parameter setting or the function of a new equation [10].

Traditionally energy system optimization models tend to optimize intertemporal based on perfect foresight as for example the well-known MARKAL [11] or the MESSAGE [12] model. However, more recently existing energy system models have been extended with myopic or so called time-step approaches as for example the SAGE [7] model which has been developed out of the MARKAL model. According to the EIA [7] the limited foresight was integrated in order to take the evolutionary nature of the energy and technology markets into account. Also as stated in [8] there has been a myopic version of the MESSAGE model developed in order to asses "the consequences of short-term decisions in the context of achieving long-term objectives". Another example is the development of a myopic model to integrate a more realistic character of projection into the energy system model IKARUS by Martinsen et al. [3,9]. Their conclusion is that consistent and plausible scenarios can be produced and analysed with the myopic approach. Comparing energy system modelling of perfect foresight and myopic foresight, Krey [10] came to the same conclusion. The perfect foresight model is especially apt to determine an economically efficient solution for a transition of the energy system, whilst considering technical and environmental restrictions. Nevertheless, it may not fully capture the decision framework relevant for real life decision makers. In reality, future costs and prices are subject to uncertainties that increase with the length of the considered time-frame [13].

As Babiker et al. [14] shows, the level of foresight influences total costs as well as investment decisions. A myopic approach may allow the model to deliver more realistic and contemporary results. Some authors argue, however, that with a myopic approach the model constructor himself has a better understanding of the future than the modelled decision maker. The latter has no information of the future at all, which may on the one hand lead to a time-delay in adjusting to changes and irreversible investments $[15,16]$. On the other hand, this makes a myopic approach more suitable than the perfect foresight approach to examine the consequences of unpredictable events, as for example the developments of $\mathrm{CO}_{2}$ allowance prices. The effect of a sudden rise in prices is softened when applying a perfect foresight approach since the optimization model knows about the upcoming price shock and can adapt the investment strategy accordingly, while with a myopic approach, the system does not know 
about future occurrences in the next period since its optimization focus covers only the current period. Thus it does not adapt to changes in advance. Keppo et al. [17] examine the influences of limited foresight on energy transitions based on the MESSAGE model and also find that considering only the current needs leads to postponing investments. According to Krey [10] those so called "lost opportunities" occur when the measurements that can be taken are time depended and have an effect or life time over decades. If there is for example the need for new generation capacities now and carbon intensive capacities are build, in 5 years it will be too late to change them into low carbon capacities even if new emission laws or costs come up. The opportunity to lower the carbon emissions of the generation system within the renovation cycle will already be lost. Krey [10] also states that the results of an optimization with perfect foresight and an optimization based on myopic foresight are very similar as long as the input parameters of the scenarios change continuously over the considered time frame. While it is possible to find the absolute optimum over the time frame with perfect foresight, price-shocks are better examined with a myopic approach in regard to real-life behaviour.

Using once the myopic and once the perfect foresight approach with an energy system model the reaction to two extreme horizons can be analysed. In the first case every period is optimized individually knowing nothing about the future while in the other extreme everything is known and an intertemporal optimum is found. Obviously, there are possible approaches in between as for example granting the model knowledge about at least one future period that is taken into account besides the current period (rolling horizon approach [18]). Those strategies of limited foresight might combine the advantages of both approaches and might lead to the most realistic prediction of the system reactions to future events. Our main target is to find a measure to lower the computing time of the energy system model PERSEUS-NET significantly without compromising the quality of our results. Therefore, we compare here the two extreme approaches.

\section{Model description}

\subsection{PERSEUS-NET}

PERSEUS-NET is a bottom-up linear optimizing energy system model including a nodal pricing based approach. It is part of the PERSEUS (program package for emission reduction strategies in energy use and supply) model family of technologybased energy and material flow optimization models that assumes perfect competition and complete information. The aim of PERSEUS-NET [19] is to minimize costs of power supply until 2030 while satisfying the exogenously given electricity demand and considering the restrictions by the underlying electricity grid. PERSEUS-NET is structured as a graph in which so called producers $(P R O D)$ form the nodes and flows form the edges in between. While the nodes and flows form the structural level of the model there is also a more aggregated level (aggregating producers and flows to regions and sectors) and a detailed level (representing reference generation units and processes-ct. Fig. 1). Within that hierarchic structure each of the producers 


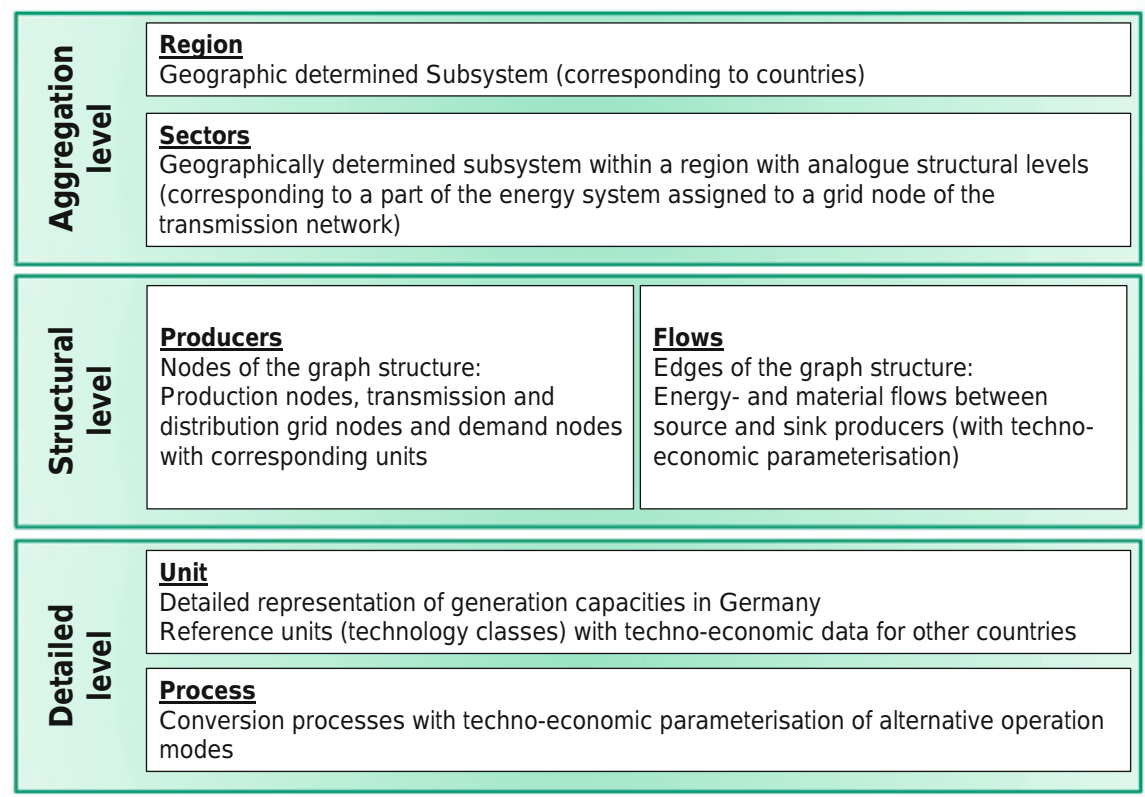

Fig. 1 Hierarchy of the model elements in PERSEUS-NET [19]

belongs to a sector which corresponds to the part of the energy system assigned to a specific grid node of the transmission network. Sectors themselves belong to so called regions which represent countries. Generation units (UNIT) allocated close to or at a grid node are assigned to the corresponding producer of that grid node. Each unit has at least one operation mode as a process (PROC). A generation unit can for example have one generation process (GENPROC) that converts coal to electricity and one other that converts coal to electricity and heat. Besides those generation processes there are also demand processes (DEMPROC) indirectly assigned to a producer.

The value of the objective function is the sum of all system relevant expenditures discounted to the base year ( $\alpha_{t}$ discount factor of year $t$ ) as shown in Eq. (1). The first summand comprises all fuel expenditures, the costs $\left(C f u e l_{i m p, p r o d}, e c\right.$ ) to import (imp) an energy carrier (ec) into the system to a specific producer (prod) are multiplied with the corresponding energy carrier flow $\left(F L_{i m p, p r o d}, e c, t\right)$. The second summand comprises the variable costs of energy conversion (Cvar proc,t) and industrial production $\left(P L_{\text {proc }, t}\right)$ for each conversion process ( proc). The third summand reflects all specific expenditures $\left(\operatorname{Cinv}_{\text {unit, }}\right)$ for the installation of new capacity (NewCap unit, $)$, fixed costs $\left(C f i x_{\text {unit }, t}\right)$ of all capacity $\left(\right.$ Capunit $\left.t_{t}\right)$ and costs $\left(\right.$ Cload $\left._{\text {unit }, t}\right)$ for load changes ( $L$ V change unit,seas -1, seas,$\left.t\right)$ from one timeslot (seas) to the next for coal, lignite and uranium units. For new units the annuity of the investment is used, thus taking into account their economic lifetime. The fourth summand represent the costs $\left(\mathrm{Ckyo}_{k y o, t}\right)$ for $\mathrm{CO}_{2}$ emission allowances $\left(\right.$ KyoCert $\left._{k y o, t}\right)$ [19]. 


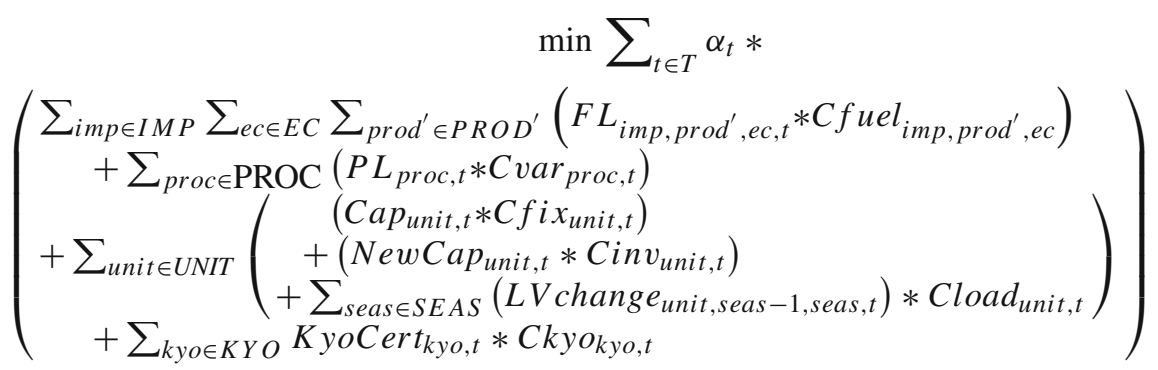

Further technical and economical characteristics are considered through 24 constraints concerning energy and material flow balances, matching supply and demand spatially and temporally as well as generating capacity restrictions, e.g. lifetimes of generating stations and timely availability. The most important once are represented in the following, for more details and information on the other constraints see [19].

With a time horizon of 2030 and a base year of 2007 in PERSEUS-NET at least every 5 year is optimised (all other years can be interpolated). A year is represented via eight days of a type consisting of weekend and weekdays for each season. These days of a type have between three and seven timeslots each. The 46 typified timeslots represent in between 1 and $22 \mathrm{~h}$ of that 8 days. The first periods (2007 and 2010) serve the model constructors for calibration and checking of the model. As the energy demand is the driving force of the model, Eq. (2) represents the corresponding restriction, which states, that electricity demand $\left(D_{t, \text { seas }}\right)$ equals the electricity flow ( $F L_{\text {prod,exp,elec,t,seas }}$ ) exported (exp) over the considered system boundaries for each producer in every timeslot and every year.

$$
\begin{gathered}
F L_{\text {prod,exp,elec }, t, \text { seas }} \geq D_{t, \text { seas }} \\
\forall \text { prod } \in \text { PROD } ; \forall \exp \in E X P ; \forall t \in T ; \forall \text { seas } \in S E A S
\end{gathered}
$$

Seasonal energy carriers $\left(E C_{\text {seas }}\right)$ such as electricity or heat are balanced via Eq. (3) Seasonal flows ( $\left.F S_{\text {prod,prod,ec,t,seas }}\right)$ and seasonal process levels $\left(P S_{\text {proc }, \text { seas }, t}\right)$ are balanced for every producer and each of the 46 time slots $(S E A S)$. The sum of the inflows of an energy carrier to a producer from another producer $\left(F S_{\text {prod', prod,ec,t,seas }}\right)$ and/or the generation of that energy carrier $\left(P S_{\text {proc,t,seas }} *\right.$ $\left.\lambda_{\text {proc,ec }}\right)$ within each time slot equals the outflows ( $F S_{\text {prod,exp,ec,t,seas }}$, $\left.F S_{\text {prod,prod }, \text { ec,t,seas }}\right)$ and use of it $\left(P S_{\text {proc }, t, \text { seas }} * \lambda_{\text {proc,ec }}\right)$ from this producer considering the efficiency of the flows and the use process ( $\eta_{\text {prod,exp,ec, },}, \eta_{\text {prod,prod }}$, ec,, , $\left.\eta_{\text {prod,ec }}\right)$.

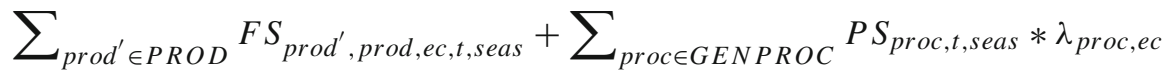

$$
\begin{aligned}
& =\sum_{\text {exp } \in \text { EXP }} \frac{F S_{\text {prod,exp,ec,t,seas }}}{\eta_{\text {prod,exp }, e c, t}}+\sum_{\text {prod }^{\prime} \in P R O D} \frac{F S_{\text {prod }, \text { prod }^{\prime}, e c, t, \text { seas }}}{\eta_{\text {prod, } \text { prod }^{\prime}, e c, t}} \\
& +\sum_{\text {proc } \in \text { DEMPROC }} P S_{\text {proc }, t, \text { seas }} * \frac{\lambda_{\text {proc }, e c}}{\eta_{\text {prod }, e c}} \\
& \forall t \in T ; \forall \text { seas } \in S E A S ; \forall \text { prod } \in P R O D ; \forall e c \in E C_{\text {seas }}
\end{aligned}
$$


Equation (4) is responsible for the energy and material flow balance of non-seasonal energy carriers $\left(E C_{n o n-s e a s}\right)$ such as coal or gas. It ensures that the yearly flows $\left(F L_{\text {prod,prod }}^{\prime}, e c, t\right)$ and process levels $\left(P L_{\text {proc }, t}\right)$ with non-seasonal energy carriers are balanced in each year the same way as the seasonal energy carriers in each time slot. Different is only that non-seasonal energy carriers can be "imported" from out of the system boundaries ( $\left.F L_{i m p, p^{\prime} o d^{\prime}, e c, t}\right)$.

$$
\begin{aligned}
& \sum_{i m p \in I M P} F L_{i m p, p^{\prime} r o d^{\prime}, e c, t}+\sum_{\text {prod }^{\prime} \in P R O D} F L_{\text {prod }^{\prime}, p r o d, e c, t} \\
& +\sum_{\text {proc } \in G E N P R O C} P L_{\text {proc }, t} * \lambda_{\text {proc }, e c} \\
& \sum_{\text {exp } \in \text { EXP }} \frac{F L_{\text {prod,exp,ec }, t}}{\eta_{\text {prod,exp,ec }, t}}+\sum_{\text {prod }^{\prime} \in P R O D} \frac{F L_{\text {prod,prod }, e c, t}}{\eta_{\text {prod,prod }, e c, t}} \\
& +\sum_{\text {proc } \in \text { DEMPROC }} P L_{\text {proc }, t} * \frac{\lambda_{\text {proc }, e c}}{\eta_{\text {prod }, e c}} \\
& \forall t \in T ; \forall \text { prod } \in P R O D ; \forall e c \in E C_{\text {non-seas }}
\end{aligned}
$$

Two further equations stating that the sum over the time slots of the seasonal process/flow levels has to be the yearly process/flow level of that process/flow complement the balancing equations.

In order to model the generation processes according to their technological characteristics there are several constrains implemented. Equation (5) for example guarantees that all processes of a unit are in each timeslot and year only used ( $\left.P S_{\text {proc,seas }, t}\right)$ within total unit capacity $\left(\mathrm{Cap}_{\text {unit }, t}\right)$, considering unit availability $\left(\right.$ Avai $\left._{\text {unit }, t}\right)$ and the length of the time slot $\left(h_{\text {seas }}\right)$. Besides, there are equations referring to the minimum the maximum full load hours of a unit, as well as to the costs for load changing. Furthermore, there are specific equations included for the use of pump storage systems and combined heating and generation units.

$$
\begin{aligned}
& \text { Cap unit }, t_{\text {t }} * \text { Avai }_{\text {unit }, t} * h_{\text {seas }} \geq \sum_{\text {proc } \in \text { PROC }} \text { unit }_{\text {proc }, t, \text { seas }} \\
& \forall t \in T ; \forall \text { seas } \in S E A S ; \forall \text { unit } \in \text { UNIT }
\end{aligned}
$$

Equation (6) refers to the capacity expansions. The installed capacity in each period equals the already existing capacity $\left(\operatorname{CapRes}_{\text {unit,t }}\right)$ in that period plus the newly build capacity. Capacity expansions are limited by exogenously given values, which for existing units mirror their actual installation. Generation units are automatically decommissioned due to their age 40 years after being commissioned.

$$
\begin{aligned}
& \text { Cap unit }, t_{\text {t }}=\text { CapRes }_{\text {unit }, t}+\text { NewCap } \text { Canit }, t \\
& \forall t \in T ; \forall \text { unit } \in \text { UNIT }
\end{aligned}
$$

These balancing and technical restrictions are complemented by equations regarding the transmission grid [20], which is represented in the model by 560 transmission 
lines that connect all power stations and grid nodes. Each neighbouring country is depict via one grid node through which the electricity exchange to and from Germany can be set. Network expansion projects are taken into account considering actual delays. Therefore the network expansions differ in comparison to EnLAG [21]. A DC (direct current) load flow approach is used to represent thermal limitations of power lines' transmission capacity. Nodal prices serve as price signals depending on both the location and time of demand. If there is not sufficient transmission capacity between certain grid nodes, there might be a surplus of generated electricity on one side of the bottleneck and a shortage on the other side, resulting in the use of more expensive power plants in the county with the shortage and higher nodal prices than in the county with the surplus.

To give a correct representation of physical location and resulting power flows, the area of Germany is subdivided into 440 administrative districts, which all have a specific load and are connected to the transmission network via grid nodes. The demand is calculated individually for each district based on the estimated development of gross domestic product and population. In order to satisfy the exogenously given demand in each district, the existing local generation system can be used or electricity can be imported from neighbouring grid nodes. To meet additional electricity demand in the system or to substitute old power plants there is the possibility to install new lignite, coal or gas power plants. Each district has a specific generation system of decentralized generating units. Larger power plants (>100 MW) are directly connected to the transmission network, and for each district the development of renewable energy generation is exogenously fixed. The overall renewable energy development in Germany is in accordance with the German pilot study [22] and is distributed to the administrative districts based on regional potentials [23]. The installation of renewable energy generators is exogenously fixed, because time and place of the generating units is in general not determined by economics alone. Renewables are modelled as base-load capacities, partially neglecting their volatile character. Due to this simplification and the rough time structure, which makes it impossible to model the advantages of quickresponse generating units, another restriction is implemented to assure that $10 \%$ of the unit capacity has to consist of peak load capacities such as pump storage systems or gas turbines.

In summary PERSEUS-NET consists of about 3 million equations and 3.4 million variables and allows the calculation of the future generation system in Germany based on different scenarios in which energy carrier prices, $\mathrm{CO}_{2}$ prices and imports are differently defined (cf. $[19,23]$ ). However, even so that it is a linear optimization model with only 46 timeslots representing a year the computing time of the model is still as long as a few days [19]. Furthermore, the growing feed-in of volatile renewable electricity leads to the need for a more detailed time structure and/or a better representation of the electricity grid [20], which would drastically increase computing time.

\subsection{Computational realization of the myopic feature}

Implementing the myopic feature in PERSEUS-NET means that the generation system and its capacity utilization are no longer optimized at once for the whole time-frame. 


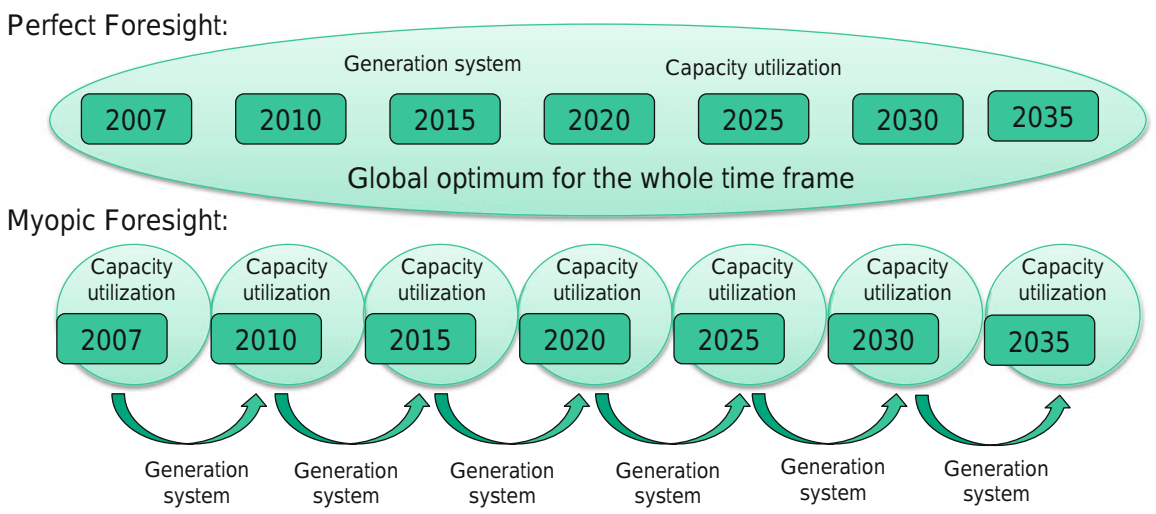

Fig. 2 Perfect Foresight approach vs. myopic approach

Instead, newly build capacities and the capacity utilization are calculated for each period individually considering the resulting generation system of the period before and the current needs of the calculated period. Figure 2 illustrates the differences.

The code of PERSEUS-NET is written in GAMS and solved with the CPLEX solver. The main challenge about switching PERSEUS-NET from perfect to myopic foresight is to automatically read the output of one period in terms of the generating system as the input for the next period. Up to now the input data was stored in a Microsoft ${ }^{\circledR}$ Access database which has been read in GAMS through include files, while the output was stored, via a GDX interface, in Microsoft ${ }^{\circledR}$ Excel. To facilitate the handover from one period to another, the database has been switched to Excel with a GDX interface between GAMS and Excel to read and write data. The program is started by opening a batch file, which first calls a GAMS program that creates a GDX file out of the database where all the scenario data has been stored, then the first part of the PERSEUS code is opened and the optimization of the first period begins. After the optimization, the resulting generation system for that period is written to an Excel sheet. Additionally all results are given to the second part of PERSEUS that creates another GDX file. Subsequent periods are sequentially started with the batch file, reading in the results from the period before, which have been stored in the myopic (time-step) database. After the last period, the batch file calls up another GAMS code that merges the GDX files of all the calculated periods to one single result file and writes it to Excel. Figure 3 illustrations the sequence of the programs/files that are started/used by the batch file.

Compared to the necessary approach for perfect foresight where the batch file only calls the GDX-Creator once, and the two parts of PERSEUS (see Fig. 4), the myopic optimization seems more sophisticated. However, the calculation time with a myopic approach is shorter than with a perfect foresight approach. This is because the solution space of linear optimization problems grows exponentially with the number of variables [24]. In the worst case that means that the computing time of the problem also grows exponentially with the number of variables. In PERSEUS-NET the calculation of seven periods at once has about seven times as many variables ( 7 times $n$ ) as the 


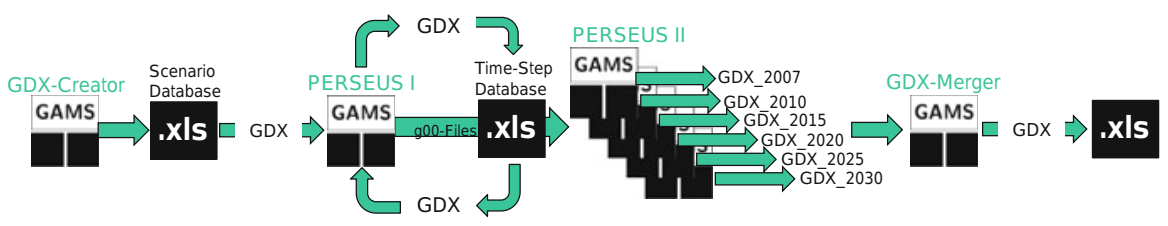

Fig. 3 Sequence of programs for the myopic optimization

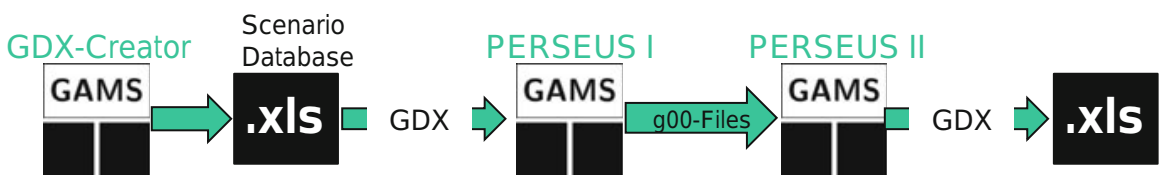

Fig. 4 Sequence of programs for the perfect foresight optimization

calculation of one single period (n variables). Hence, instead of a computing time that is in the worst case exponentially proportional to seven times the number of variables of one period ( 7 times $n$ ) the computing time of each of the seven periods is only exponentially proportional to $\mathrm{n}$ variables.

\section{Case study based on the German energy system}

\subsection{Scenario definition}

In order to assess the deviations in results both modelling approaches are applied to two scenarios. A first scenario, the reference scenario, is used to analyse the consistency of the results when input factors such as resource prices have no major jumps in their development. Energy carrier price developments for Germany are based on the world energy outlook 2008. The European carbon prices are assumed to increase from $8 € / \mathrm{tCO}_{2}$ in 2007 to $45 € / \mathrm{tCO}_{2}$ in 2030 [1]. The second scenario, the $\mathrm{CO}_{2}$ shock scenario, is analysed in order to assess the reaction of both approaches to sudden changes. Input parameters are identical to the ones described in the reference scenario except for the development of $\mathrm{CO}_{2}$ prices. The price shock is modelled by raising the prices in 2030 to double the prices in the reference scenario. Figure 5 shows the development of input factors.
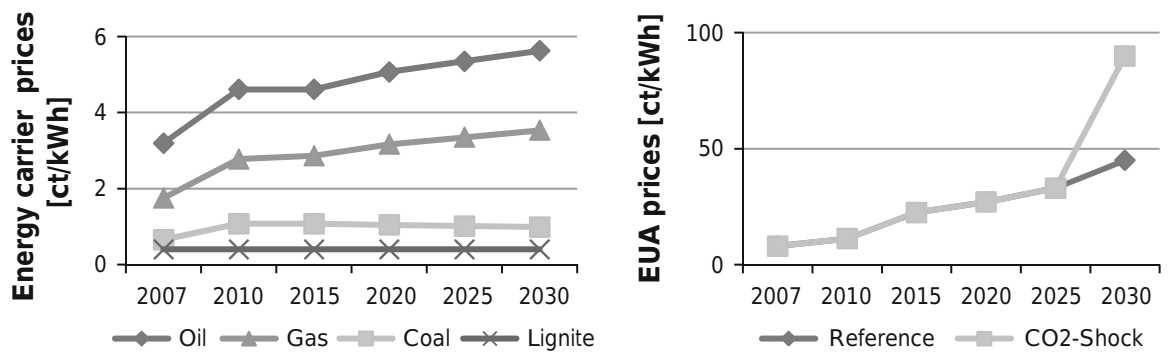

Fig. 5 Energy carrier and $\mathrm{CO}_{2}$ price development for Germany $[1,25]$ 
The starting generation system for both scenarios is originally based on [26] and has been constantly updated with information among others based on experts, web sites of operators and [27]. In total over 260 large units (>100 MW) are modelled at specific grid nodes and about 1,600 small units are geographically combined and assigned to administrative districts (cf. [19]). The development of the renewables is exogenously given and based on [22], in total the installed renewable generating capacity increases from about $60 \mathrm{GW}$ in 2010 up to $90 \mathrm{GW}$ in 2030. The nuclear fade out is considered as completed until 2022 as stated in the current German legislation. Electricity demand is slightly decreasing until 2030 compared to today, the numbers and geographical distribution are taken from [19]. Further information about input data such as the inter-regional power exchange, the transmission grid or the technoeconomic characteristics of the investment options can also be found in [19].

\subsection{Results}

Applying the myopic approach to the PERSEUS-NET model has a significant effect on the calculation time compared to the perfect foresight approach. The calculations show that it is possible to solve a model that took $26 \mathrm{~h}$ in perfect foresight mode within $2.5 \mathrm{~h}$ in myopic foresight mode. This advantage might however cause some changes in the results: The global optimum is not guaranteed anymore and the difference might be substantial - depending mainly on the assumed price development. The following description of scenario results will focus on the developments in the years 2025 and 2030, as most differences are to be found there.

\subsubsection{Reference scenario}

In the following, the results of the limited foresight model and the perfect foresight model under reference conditions are compared. Regarding capacity development, the results show moderate differences between the two modelling approaches. The change in newly built capacities can be seen in Fig. 6. These minor changes have their origin in the moderate rises in energy carrier prices. The differences between the two models regarding newly installed capacities are about $6-8 \%$ for gas and about $3 \%$ for lignite generation capacities. However, taking into account the already existing power plants,

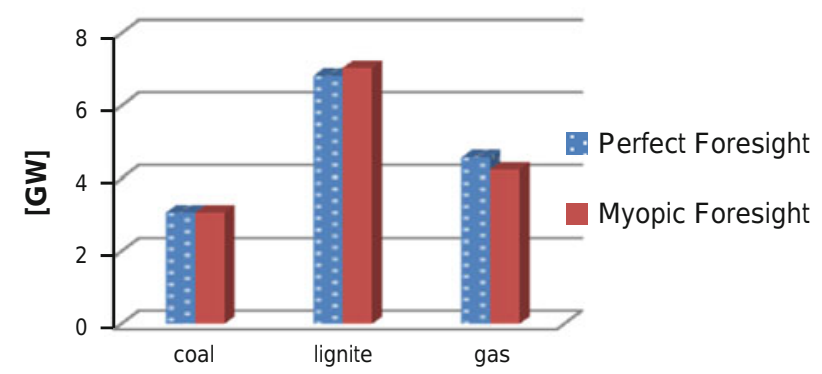

Fig. 6 In 2025 and 2030 newly build thermal capacities in Germany (reference scenario) 

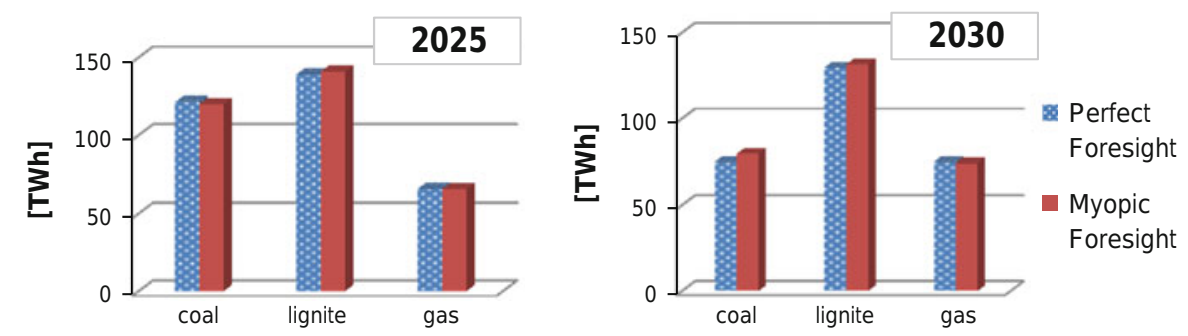

Fig. 7 German thermal electricity generation in 2025 and 2030 (reference scenario)

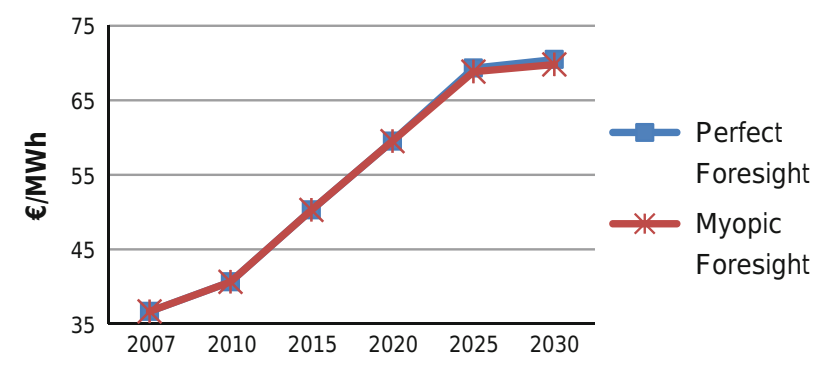

Fig. 8 Average marginal generation costs in Germany (reference scenario)

the differences between the myopic and the perfect foresight approach only result in a deviation of $1.3 \%$ in installed capacities of lignite plants and $0.4 \%$ in installed gas-fired capacity.

Regarding electricity generation, the results are also compared only for the energy carriers coal, gas and lignite as the levels for all other energy carriers are equal. In Fig. 7, total electricity generation per energy carrier is depicted. In 2025, the differences are rather small at only about $1 \%$. However, in 2030 slightly greater deviations can be witnessed. Generation from coal is down by $1.5 \%$ in the myopic model while generation from lignite is up by $1.4 \%$. These deviations are due to the development in energy carrier prices and $\mathrm{CO}_{2}$ price developments which the perfect-foresight based model can anticipate and the myopic model cannot. Hence, the myopic model invests in lignite units that have higher installation costs than coal units, thus neglecting that lignite power generation is more $\mathrm{CO}_{2}$ emission intensive than coal and is therefore more affected by the (slightly) increasing $\mathrm{CO}_{2}$ prices. The opposite is true for the development of coal and gas generation capacity investment decisions.

As can be seen in Fig. 8, the slightly higher generation from lignite, instead of coal, results in slightly lower average marginal costs in the case of the myopic approach. However, the average yearly marginal costs are very similar in both models and rise from $38 € / \mathrm{MWh}$ in 2007 to about $70 € / \mathrm{MWh}$ in 2030 . This strong increase is mainly enhanced by the nuclear fade-out completed in 2025 and the increase in energy carrier prices. The lower marginal costs of the myopic approach are due to the fact that investments are not reflected in marginal costs. Thus, the slightly higher lignite generation capacity in the myopic model leads to slightly lower marginal costs. For the same 
reason the $\mathrm{CO}_{2}$ emissions also differ slightly: while the myopic model calculates up to $245 \mathrm{Mt} \mathrm{CO}_{2}$ in 2025 and $205 \mathrm{Mt} \mathrm{CO}_{2}$ in 2030 the perfect foresight approach result to emissions of $245 \mathrm{Mt} \mathrm{CO}_{2}$ in 2025 and $204 \mathrm{Mt} \mathrm{CO}_{2}$ in 2030.

Due to the similar results regarding location and capacity of new generation investments, there are also almost no differences to be seen in transmission bottlenecks and regional marginal costs.

\subsection{2 $\mathrm{CO}_{2}$ shock scenario}

To further analyse possible differences between the modelling approaches, a second scenario is calculated, integrating a sudden price shock. Regarding capacity development, there is a significantly different development to be seen in 2025. Since the perfect foresight approach is already "informed" about the $\mathrm{CO}_{2}$ price jump in 2030, almost no more lignite plants are built because of their high specific $\mathrm{CO}_{2}$ emissions. Figure 9 shows the newly installed capacity in the years 2025 and 2030 for both approaches. The investments in coal based generation capacity in 2030 are to a large extent CCS enhanced technologies. In the perfect foresight model, 13.5 GW are CCS coal technology and in the myopic model 9.3 GW are CCS coal capacities.

Due to the different mixes of installed power plants, in 2025 with the perfect foresight approach 34 TWh additional electricity is generated from coal and 5 TWh more gas which are generated with lignite instead with myopic foresight (Fig. 10). In 2030 this changes to 32 TWh generation from coal and 2 TWh from gas that are in the myopic approach subsidized by lignite generation. $\mathrm{CO}_{2}$ emissions develop accordingly, resulting in $21 \%$ higher emissions of the myopic approach in 2030, the period in which prices have risen (Fig. 11). While perfect foresight has in 2030 emissions of $126 \mathrm{Mt} \mathrm{CO}_{2}$, which is only about $60 \%$ of the reference value, myopic emissions result with $152 \mathrm{Mt}$ to about $75 \%$ of the former value.

Comparing the two models, the myopic model invests in 2025 too heavily in lignite power generation, missing out on the opportunity to invest in the not as carbon intensive coal generation instead. This leads to a high share of lignite based power generation capacity in the generation system in 2030 . The perfect foresight model on the other hand invests into a more balanced generation system leading to distinctly lower carbon emissions and total costs of energy supply in 2030 .
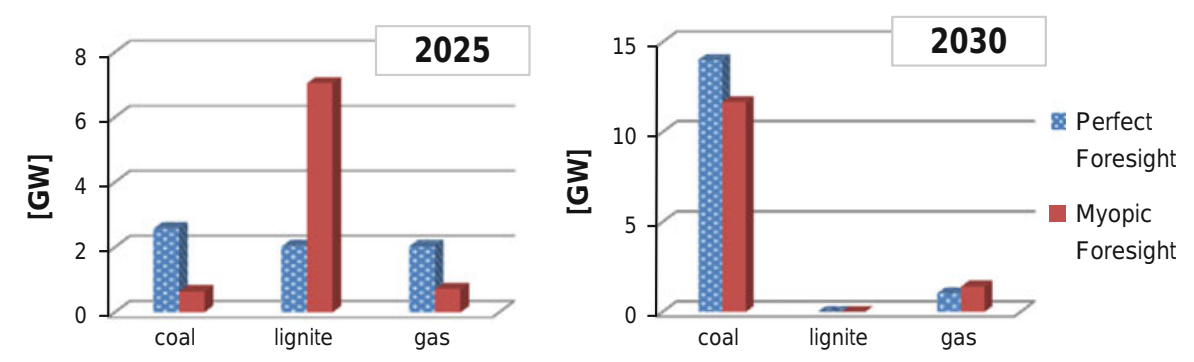

Fig. 9 In 2025 and 2030 newly build thermal capacities in Germany $\left(\mathrm{CO}_{2}\right.$ shock scenario) 

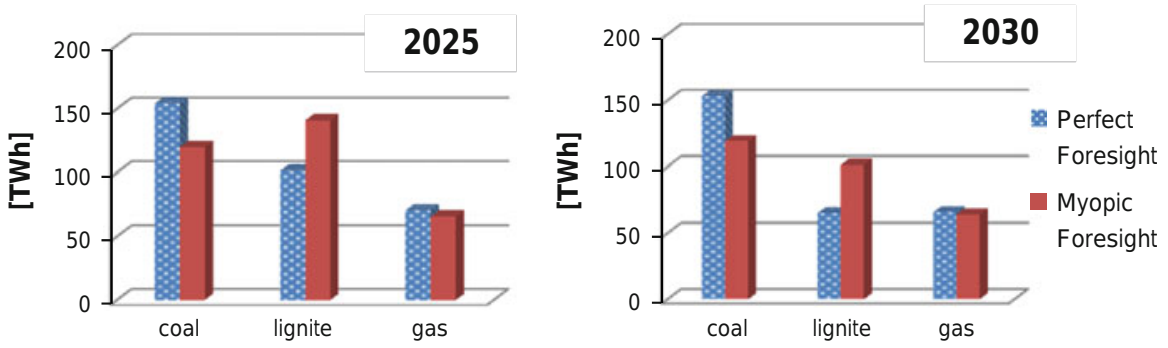

Fig. 10 German thermal electricity generation in 2025 and $2030\left(\mathrm{CO}_{2}\right.$ shock scenario)

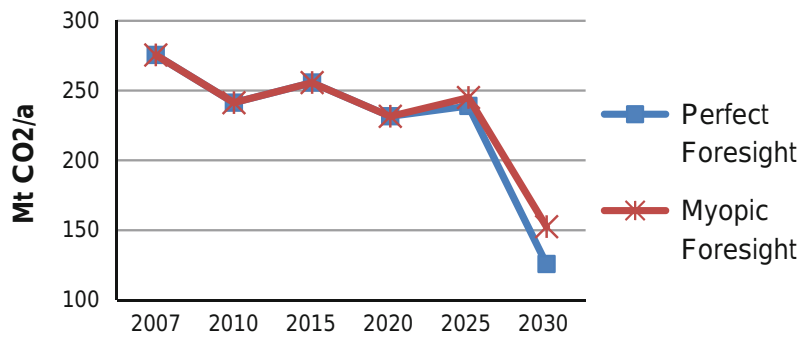

Fig. $11 \mathrm{CO}_{2}$ emissions in Germany $\left(\mathrm{CO}_{2}\right.$ shock scenario)

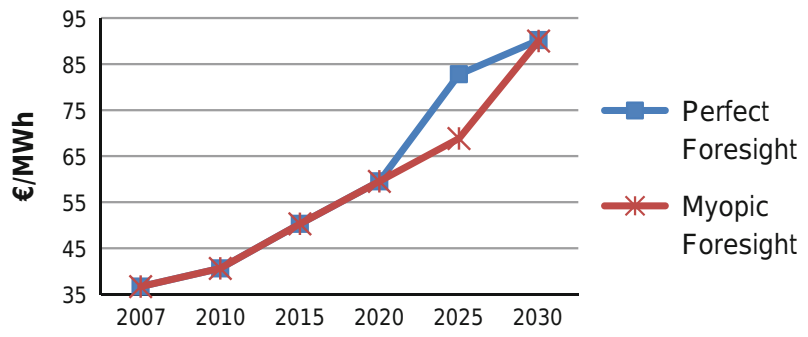

Fig. 12 Average marginal generation costs in Germany $\left(\mathrm{CO}_{2}\right.$ shock scenario)

The different generation capacities also result in different average marginal prices in 2025. As to be seen in Fig. 12 with perfect foresight the average marginal price is at $83 € / \mathrm{MWh}$, while it is only $69 € / \mathrm{MWh}$ in the myopic approach.

\section{Discussion}

Concluding from the results presented in the last chapter, it can be found that the advantages and draw-backs of the two analysed approaches depend on the considered scenario.

On the one hand there is the case that the input parameters are steady. In this case the results are similar. Hence both approaches are equally adequate for scenario analysis with continuously changing parameters. However, the myopic approach has the substantially shorter computing time. 
On the other hand, a sudden jump of exogenous parameters in the scenario assumptions leads to significantly different results of the two approaches. This could for example happen based on the occurrence of a new technology or the $\mathrm{CO}_{2}$ price development. With the perfect foresight approach the global optimum is calculated, showing the ideal reaction of the system to sudden events, partially even before its occurrence. Therefore, the results of the perfect foresight approach can be considered as an upper limit to the performance of a system in a certain scenario. Though, if the intention of the scenario is to analyse a more realistic reaction of the system to unforeseen sudden events this can better be done with the myopic approach. The myopic approach determines for each period the optimum for the current conditions without anticipating any changes in future periods. It has to be kept in mind that in reality even this instantaneous reaction to sudden price changes would need major advance planning because of the construction time that is not explicitly modelled. If it is known that there are structural changes to come, as for example a rise in $\mathrm{CO}_{2}$ prices due to a known cut in the cap, the results of the myopic approach would be suboptimal compared to perfect foresight as they would not mirror that knowledge. The results include costs of a delayed reaction to the known events. Furthermore, lost opportunities because of the total lack of knowledge of future events can be identified through a comparison of the myopic results to the global optimum. Accordingly, both approaches are especially suited to different types of problems thus the two versions can be seen as complimentary.

Nevertheless, using a myopic approach, it has to be kept in mind that the characteristic of the optimization shifts more towards a simulative approach and that the result can differ to the intertemporal optimum. Furthermore, having perfect information within the considered period and no information about future periods does not seem to be more realistic and the model results loose the advantage of being interpretable as the intertemporal optimum. Then again, the uncertainties increase in the German energy sector because of the shift towards renewables, making perfect foresight less probable. As in long term energy system models structural or technological changes are not precisely predictable in time, the disadvantage of the myopic approach of not having the global optimum seems to become somewhat less significant for the "quality" of the forecasts of the model. Hence, a myopic approach is suitable to analyse how short-term decision making influences the long term energy system development. It can be used instead of the perfect foresight approach in scenarios with monotonic developments of prices in order to reduce the required computing time.

\section{Conclusion and outlook}

Since the complexity of energy systems increases due to rising shares of renewable and decentralised electricity provision, the complexity of energy system models, representing these real world phenomena, increases as well. The resulting computing time has become a major obstacle in today's modelling of energy systems. To keep models feasible, trade-offs between exactness and computing time have to be made. In this paper the function to switch from a perfect foresight approach to a myopic approach has been integrated into the energy system model PERSEUS-NET in order 
to compare the assets and drawbacks of a myopic modelling approach against the gains in computing time. It is shown, that in scenarios with a steady development of parameters the differences between the results are negligible when using the myopic instead the perfect foresight approach, but with much shorter computing time.

Currently, the complexity of energy models rises due to the increasing volatile feed-in, especially if stochastic parameters were taken into account, making the tradeoff between exactness and computing time even more crucial. To account for the evolutionary character of modern energy systems, myopic versions, have been already developed for traditional energy system models such as MESKAL or MESSAGE.

Through the implementation of the myopic approach in PERSEUS-NET the computing time could be reduced to about a tenth of the computing time with perfect foresight. It is planned to use the gained flexibility to generate new model versions that concentrate on specific consequences of an increased share of electricity by renewable energy resources such as the need for a higher time resolution, storage systems or the interaction with the gas transmission system, as natural gas is also a grid-bound energy carrier. Because of the advantage of shorter calculation time, the myopic approach is suitable for complex energy system models with a high computing time-especially with a monotonic development of prices. As the future energy system will consist of an increasing share of renewables and decentralised generation units an increasing time and geographical resolution is needed. Hereby the complexity and therefore the computing time increase significantly. The integration of characteristic feed-in profiles of renewable energies and more time slots representing a calendar year can be done with accessible time for calibrating and calculating the model. Future research should therefore integrate a high spatial and temporal resolution making more realistic modelling of future energy systems possible.

\section{References}

1. Möst, D., Genoese, M., Eßer, A., Renz, O.: European electricity and emission market modeling-the design of emission allocation plants and its effects on investment planning. Paper presented at the 5th Conference on European electricity market (EEM), Lisbon (2008)

2. Loulou, R., Remme, U., Kanudia, A., Lehtila, A., Goldstein, G.: Documentation for the TIMES model. http://www.iea-etsap.org/web/Documentation.asp (2005)

3. Martinsen, D., Krey, V., Markewitz, P., Vögele, S.: A new dynamical bottom-up energy model for Germany: model structure and model results. Paper presented at the 6th IAEE European Conference, Zürich (2004)

4. Rosen, J.: The future role of renewable energy sources in European electricity supply: a model-based analysis for the EU-15. Dissertation, Universität Karlsruhe, Karlsruhe (2008)

5. Nagl, S., Fürsch, M., Paulus, M., Richter, J., Trüby, J., Lindenberger, D.: Energy policy scenarios to reach challenging climate projection targets in the German electricity sector until 2050. Utility Policy 19(3), 8 (2011)

6. BMWi, BMU: The Federal government's energy concept of 2010 and the transformation of the energy system of 2011. In: N.C.a.N.S. (ed) Federal Ministry of Economics and Technology and Federal Ministry for the Environment, Berlin (2011)

7. EIA: System for the analysis of global energy markets (SAGE). Model documentation report, energy information administration, U.S. Department of Energy (2003)

8. IIASA: Myopic MESSAGE - a model to analyze energy systems and to evaluate policies over a short-to-medium time horizon. http://www.iiasa.ac.at/web/home/research/researchPrograms/Energy/ MYOPIC-MESSAGE.en.html (2012) 
9. Martinsen, D., Krey, V., Markewitz, P., Vögele, S.: A time step energy process model for Germany: model structure and results. Energy Stud. Rev. 14(1), 3 (2006)

10. Krey, V.: Vergleich kurz- und langfristig ausgerichteter Optimierungsansätze mit einem multiregionalen Energiesystemmodell unter Berücksichtigung stochastischer Parameter. Dissertation, RuhrUniversität Bochum (2006)

11. Fishbone, L.G., Abilock, H.: MARKAL: a linear programming model for energy system analysistechnical description on the BNL version. Intern. J. Energy Res. 5/4, 21 (1981)

12. Messner, S.: User's guide for the matrix generator of message II: model description and implementation guide. IASA WP 84-71a, Laxenburg (1984)

13. Keppo, I., Strubegger, M.: Short term decisions for long term problems: the effect of foresight on model based energy systems analysis. Energy 35(5), 2033-2042 (2010). doi:10.1016/j.energy.2010. 01.019

14. Babiker, M., Gurgel, A., Paltsev, S., Reilly, J.: Forward-looking versus recursive-dynamic modeling in climate policy analysis: a comparison. Econ. Model. 26, 14 (2009)

15. Enzensberger, N.: Entwicklung und Anwendung eines Strom- und Zertifikatmarktmodells für den europäischen Energiesektor. Dissertation, Universität Karlsruhe (2003)

16. Schönfelder, M., Jochem, P., Fichtner, W.: Energiesystemmodelle zur Szenarienbildung - Potentiale und Grenzen. In: Dieckhoff, C., (ed.) Energieszenarien. Konstruktion, Bewertung und Wirkung "Anbieter" und "Nachfrager" im Dialog. KIT Scientific Publishing, Karlsruhe (2011)

17. Keppo, I., Strubegger, M.: Implications of limited foresight and sequential decision making for longterm energy system planning: an application of the myopic MESSAGE model. In: Interim Report IR-09-006. International Institute for Applied Systems Analysis, Laxenburg (2009)

18. Chand, S., Hsu, V.N., Sethi, S.: Forecast, solution, and rolling horizons in operations management problems: a classified bibliography. Manuf. Serv. Oper. Manag. 4(1), 25-43 (2001). doi:10.1287/ msom.4.1.25.287

19. Eßer-Frey, A.: Analyzing the regional long-term development of the German power system using a nodal priceing approach. Dissertation, Karlsruher Institute of Technologie (2012)

20. Nolden, C., Schönfelder, M., Eßer-Frey, A., Bertsch, V., Fichtner, W.: Network constraints in technoeconomic energy system models. Energy Systems (2013). doi:10.1007/s12667-013-0078-0

21. BGBI: EnLAG - Gesetz zur Beschleunigung des Ausbaus der Höchstspannungsnetze. In: Bundesanzeiger (ed.). p. 2870. Bundesgestzblatt I (2009)

22. BMU: Pilot study 2010. In: Ministry, G.F.E. (ed.). Berlin (2010)

23. Eßer-Frey, A., Fichtner, W.: Analyzing the regional development of the German power system using a nodal pricing approach. Paper presented at the 8th Conference on the European Energy Market (EEM), Zagreb (2011)

24. Gass, S.I.: Linear programming: methods and applications, 5th edn. Dover Publications (2010)

25. IEA: World energy outlook. International Energy Agency, France (2008)

26. Platts: World electric power plants database. Platts, Washington (2005)

27. Nöther, A.: Kraftwerke-online. Database, http://www.kraftwerke-online.de (2012) 


\section{Repository KITopen}

Dies ist ein Postprint/begutachtetes Manuskript.

Empfohlene Zitierung:

Babrowski, S.; Heffels, T.; Jochem, P.; Fichtner, W.

Reducing computing time of energy system models by a myopic approach. 2014. Energy systems, 5.

doi:10.554/IR/1000045137/post

Zitierung der Originalveröffentlichung:

Babrowski, S.; Heffels, T.; Jochem, P.; Fichtner, W.

Reducing computing time of energy system models by a myopic approach. 2014. Energy systems, 5 (1), 65-83.

doi:10.1007/s12667-013-0085-1 